\title{
To Belong or Not to Belong; A Key Factor in Students' Learning during COVID-19 Pandemic
}

\author{
Sobia $\mathrm{Ali}^{*}$ \\ ${ }^{1}$ Department of Health Profession Education, Liaquat National Hospital and Medical College, Karachi, Pakistan
}

The COVID-19 pandemic had an undeniable effect on global health services; causing a level of instability in medical education never seen before. Several changes were done to address the imminent challenge of closure and improving the durability of education systems. The primary shift was to plan and deliver learning sessions where students and teachers are geographically remote from each other. Online synchronous instruction sessions were quickly introduced using platforms like Zoom and Microsoft Team [1]. Although these efforts contributed to the efficient delivery of content, they also caused instructors, and learners to struggle with the process. On one hand, some teachers were unprepared for such a significant shift in their teaching methods while on the other hand, students found the transition from traditional classes to hybrid/blended learning to be more difficult than expected $[1,2]$. Among several obstacles that students faced are limited internet access and availability, a lack of cutting-edge technology, and the lack of traditional classroom socialisation with both teachers and classmates.

The foremost challenge of online synchronous sessions faced by the students is the feeling of alienation, most likely as a result of being outside the protective system of a college or hospital setting, creating a sense of discomfort. This is because educational theories accept that learning is a social event and that people do not learn in isolation. Socialization plays an important role in students learning and professional identity formation and belongingness is found to be a key factor that develops this socialization [3]. Individual perception of belonging to an institution and the learning environment was found to be a factor in commitment and learning success. Evidence indicates that a lack of sense of belonging has an effect on learning motivation, identity development, and well-being. Belonging is often regarded as a powerful predictor of stress, satisfaction with the learning process, self-directed learning, self-esteem, and ultimately motivation [3]. Students who feel a strong sense of belonging in their educational settings are more involved and inspired in their academic activities, while students who do not have a

*Corresponding author: Sobia Ali, Department of Health Profession Education, Liaquat National Hospital and Medical College, Karachi, Pakistan; Email: sobia.a@lnh.edu.pk

Received: April 28, 2021; Revised: May 18, 2021; Accepted: May 20, 2021 DOI: https://doi.org/10.37184/lnjpc.2707-3521.3.3 sense of belonging are considered to have low self-esteem and low satisfaction, which can contribute to anxiety and depression [3, 4].

Students' institutional engagement, involvement, and connection with a diverse group of peers and seniors foster a sense of belonging that plays a vital role in their academic growth. They are more likely to engage in the learning process when they feel more connected. A study conducted by Hoffman et al. indicated that students' sense of belonging is dependent on their experience of being cared for by peers, faculty, and other staff members. Also, competence could only be achieved if students' core needs such as belonging were fulfilled in a healthy self-concept [5].

It's thus critical for organizations to comprehend the factors and plan in such a way that can help students develop a stronger sense of belonging, solve problems of unfamiliarity, and develop stronger relationships with their peers, teachers, and learning environment. An optimal curriculum should not only cater to the material and content to be provided but also plan for robust support services to help distant students build a sense of belonging. Although student support services are an age-old resource, they are needed to be remodelled to fit this unprecedented era of seclusion. An ideal support program for distant students should deal with three areas: Cognitive, emotional and organizational $[6,7]$.

1. Cognitive or academic support assists students to develop learning and test-taking skills. Frequent feedback, efficient use of a learning management system for resource sharing and discussion forums should be encouraged so that students can be active members of the learning community.

2. Organizational support can assist students in effectively managing their studies. This necessitates careful time management, keeping up with the speed of course, and balancing studies, family life, and other responsibilities.

3. Emotional support involves assisting students in developing learning inspiration, self-confidence in their abilities as students, and learning stress management strategies. 
Thus, medical schools should provide a dedicated counseling unit with academic and non-academic personnel (including trained counsellors) who are ready to offer academic, social, and emotional support to students on a daily basis. This will improve their chances of academic success.

If not handled properly, these obstacles can affect students' sense of identity, which can have a negative impact on their academic performance.

\section{REFERENCES}

1. Alsoufi A, Alsuyihili A, Msherghi A, Elhadi A, Atiyah $H$, Ashini $A$, et al. Impact of the COVID-19 pandemic on medical education: Medical students' knowledge, attitudes, and practices regarding electronic learning. PloS One 2020; 15: e0242905.

2. Zalat MM, Hamed MS, Bolbol SA. The experiences, challenges, and acceptance of e-learning as a tool for teaching during the
COVID-19 pandemic among university medical staff. PloS One 2021; 16: e0248758.

3. Vivekananda-Schmidt $P$, Sandars J. Belongingness and its implications for undergraduate health professions education: a scoping review. Educ Prim Care 2018; 29: 268-75.

4. Hoffman M, Richmond J, Morrow J, Salomone K. Investigating "sense of belonging" in first-year college students. J Coll Stud Ret 2002; 4: 227-56.

5. McAvoy V, Waite M. Belongingness: Student ODPs' learning experiences in clinical placements. J Perioper Pract 2019; 29: $17-23$.

6. Simpson O. Supporting students for success in online and distance education. 2014 3rd ed. London: Routledge 2014.

7. Shikulo L, Lekhetho M. Exploring student support services of a distance learning centre at a Namibian university. Cogent Soc Sci 2020; 6: 15 